\title{
LIBERTAD RELIGIOSA, LIBERTAD DE PROFESIÓN Y MATANZA DE ANIMALES (comentario a dos recientes sentencias del Tribunal Constitucional Alemán y del Tribunal Europeo de Derechos Humanos)
}

\author{
JOAQUIN BRAGE CAMAZANO*
}

\author{
SUMARIO \\ 1. Exposición del problema y algunas consi- \\ deraciones preliminares \\ 2. El ámbito normativo de los derechos fun- \\ damentales afectados \\ 3. Intervención en el derecho fundamental \\ 4. Justificación conforme a la LF o conforme \\ al CEDH \\ 5. Consideraciones finales
}

\section{EXPOSICIÓN DEL PROBLEMA Y \\ ALGUNAS CONSIDERACIONES PRELIMINARES}

Hoy en día existe, sin duda, consenso en nuestras sociedades acerca de la necesidad de proteger a los animales y evitarles a toda costa sufrimientos innecesarios, en particular, también, en el modo de ejecutarlos para su consumo humano como alimento. Esta idea básica plantea, sin embargo, problemas con relación a determinadas prácticas rituales en la matanza de animales que algunos ciudadanos, mayoritariamente extranjeros (minorías) en nuestras sociedades en Europa, pretenden llevar a cabo por entender que sus creencias religiosas así se lo exigen (musulmanes y judíos). Surge así un conflicto entre el principio general de protección estatal de los animales, que impide su

* Doctor Europeo en Derecho (UCM). Departamento de Derecho Constitucional. Universidad Complutense de Madrid. 
matanza sin anestesia, y la alegación de la libertad de creencias por parte de determinados ciudadanos que pretenden amparo del Estado para que se admitan determinadas matanzas rituales ${ }^{1}$ sin anestesia de animales en la medida en que sus creencias así se lo exijan ${ }^{2}$. A ello debe añadirse, allá donde rija como derecho constitucional, el juego de la libertad de profesión en el caso de quienes profesionalmente pretenden llevar a cabo tales matanzas, bien para ejercer su profesión conforme a las propias convicciones religiosas, bien simplemente para ejercerla conforme a las creencias religiosas de (algunos de) sus potenciales clientes; y también ha de tenerse en cuenta la posible alegación de la igualdad jurídica cuando a los seguidores de determinadas creencias religiosas se les permita excepcionalmente la matanza sin anestesia, mientras que a los seguidores de otras creencias religiosas (incluso, aunque sólo sean distintas corrientes dentro de una misma religión) se les prohíbe esa misma conducta, especialmente cuando estos últimos representan a un sector minoritario (a veces, dentro, a su vez, de una minoría).

Este es, a grandes rasgos, un conflicto que se plantea, y se planteará cada vez más, en las contemporáneas sociedades europeas y al que se han tenido que enfrentar en tiempo reciente, entre otros, el Tribunal Europeo de Derechos

1. En estas matanzas rituales se ofrecen a la divinidad los animales sacrificados, a los que, tras ser bendecidos, se les corta el cuello, matándolos con un cuchillo muy afilado de modo tal que se produce un corte inmediato, limpio y profundo que atraviesa la tráquea, el esófago, las arterias carótidas y las venas yugulares de forma tal que se permita fluir hacia el exterior la mayor cantidad posible de sangre. Christine Langenfeld, "Germany", International Journal of Constitutional Law, núm. 1, vol. 1, 2003, pp. 141, n. 2. Los métodos rituales de matanza -islámico, jatka y judíoentrañan un solo acto de matanza y desangrado: todos consiguen un alto grado de desangrado y pretenden ser humanos. El método jatka (practicado por los sijs y también por los punjabis, rathads y gurkas de la India y ciertas comunidades tribales de parte de Asia suroriental) consiste en cortar la cabeza de un golpe de espada. Los métodos islámico (halal) y judío (kosher) consisten en cortar la garganta con un cuchillo, con uno o tres golpes, respectivamente: el animal pierde rápidamente el conocimiento. Frente a ello, los métodos no rituales de matanza consisten en cortar la garganta y degollar al animal desangrándolo hasta que muera pero con un acto preliminar que consiste en inmovilizar y aturdir o atronar al animal para que quede inconsciente antes de colgarlo de un carril de desangrar. Sobre ello, véase Frederick Veall, Estructura y funcionamiento de mataderos medianos en países en desarrollo, Estudio FAO de Producción y sanidad animal, núm. 97, Organización de las Naciones Unidas para la Agricultura y la Alimentación, Roma, 1993, apartado 5 ("Degüello y desangrado"), http://www.fao.org/DOCREP/004/T0566S/T0566S05.htm\#ch5.

2. En el caso de España, el Real Decreto 54/1995, de 20 de enero, sobre protección de los animales en el momento de su sacrificio o matanza (que transpone la Directiva 93/119/CE, del Consejo, de 22 de diciembre) establece como requisito general que el sacrificio (matanza con sangrado) de solípedos, rumiantes, cerdos, conejos y aves de corral ha de hacerse de modo que se les aturda antes de su sacrificio, o se les dé muerte de forma instantánea, pero determina al unísono que tal requisito no será exigible, aparte de alguna otra excepción que aquí no importa, "en el caso de animales que sean objeto de métodos particulares de sacrificio, requeridos por determinados ritos religiosos". Su Disposición Adicional Segunda establece: "La autoridad religiosa reconocida por la legislación vigente, por cuenta de la cual se efectúen sacrificios, será competente para la ejecución y el control de las disposiciones particulares aplicables al sacrificio conforme a determinados ritos religiosos. En lo que se refiere a estas disposiciones, dicha autoridad actuará bajo la responsabilidad del veterinario oficial, tal como se define en el artículo 2 del Real Decreto $147 / 1993$, de 29 de enero, por el que se establecen las condiciones sanitarias de producción y comercialización de carnes frescas". 
Humanos (STEDH, de 27 de junio de 2000, caso de la "asociación judía ultraortodoxa minoritaria "3) y el Tribunal Constitucional Federal alemán (STCFA de 15 de enero de 2002, caso del "carnicero turco musulmán" ${ }^{4}$ ) en dos supuestos distintos, pero con grandes analogías o puntos sustanciales de conexión, llegando, sin embargo, ambas instancias jurisdiccionales a soluciones diversas, tanto en su fundamentación como en el resultado concreto alcanzado, pues mientras el TCFA consideró que la libertad religiosa y profesional ${ }^{5}$ amparaba a un carnicero musulmán no nacional a fin de llevar a cabo sacrificios sin anestesia de animales para consumo humano, el TEDH, por el contrario, no amparó a una comunidad judía ultraortodoxa a la que se había denegadó una autorización administrativa especial para proceder al sacrificio ritual de animales sin anestesia de una forma distinta, y más rigorista y exbaustiva, a la autorizada por las autoridades francesas a la comunidad judia mayoritaria. Así pues, en ambos casos se autorizaba a los creyentes (judíos o musulmanes) a practicar sacrificios rituales sin anestesia de animales por motivos religiosos, pero en el caso a resolver por el TEDH no se autorizó a un sector minoritario de la comunidad religiosa afectada (la judía, ya una minoría de por sí) a realizar tales sacrificios rituales con la exhaustividad y alcance que les exigían sus creencias religiosas (examen de los pulmones de los animales sacrificados por si tuvieran sangre). Así las cosas, no habría, aparentemente, una contradicción profunda entre una y otra resolución, por referirse a supuestos distintos cada una de ellas. Sin embargo, se verá luego que una y otra resolución reposan en fundamentaciones incompatibles entre sí, en concreto en una concepción de la libertad religiosa bien distinta en uno y otro caso.

Es importante precisar también en este momento que, a la hora de analizar estas sentencias, se utilizará el "modelo germánico" de examen de las cuestiones relativas a los derechos fundamentales, método que responde al esquema, de aplicación en tantos ámbitos del Derecho, "regla-excepción", esquema que, proyectado sobre este campo, conlleva que la libertad (esto es, el derecho fundamental de que se trate) es la regla y sus limitaciones la excepción. Este método seguido en Alemania, hoy totalmente consolidado y con el que está familiarizado no ya cualquier jurista, sino cualquier estudiante de Derecho de aquel país, distingue, en el análisis de cualquier cuestión relativa a una limitación a los derechos fundamentales, tres fases escalonadas ${ }^{6}$ a) Ámbito

3. STEDH de 27 de junio de 2000 (caso de la "Asociación litúrgica judía").

4. BVerfGE 104, 337.

5. Sobre la libertad de profesión en Alemania, donde tiene carácter de derecho fundamental y además una gran importancia práctica, en contraste con lo que ocurre en España y tantos otros países europeos, véase nuestro trabajo uLa libertad de profesión en el marco de la teoría general alemana de los derechos fundamentales", Revista de la Facultad de Derecho de la Universidad Complutense de Madrid, número 96 (Anuario), pp. 9 ss. Para comprender la STCFA comentada aquí es necesario tener una idea previa del alcance de dicho derecho fundamental en Alemania, algo que aquí hemos de dar por presupuesto.

6. En efecto, el método mencionado es de aplicación escalonada, pues se basa en un examen por escalones o fases, de manera que lo que hay que determinar en primer lugar es si el 
normativo o de protección, también llamado, por analogía con los «tipos penales", "tipo", o supuesto de hecho, del derecho fundamental"; b) Intervención o

supuesto de hecho de que se trate, y que se dé en la realidad, encaja o no en el ámbito normativo o contenido prima facie protegido del derecho fundamental: si no encontrara cobertura en el mismo, habría que detener el examen por no estar ya ante una cuestión de derechos fundamentales, mientras que si encontrara cobertura en dicho ámbito normativo habría que pasar ya a la segunda fase de examen. En esta segunda fase, hay que constatar si en el caso concreto ha existido una intervención o injerencia en el ámbito protegido del derecho fundamental, de tal manera que si se considera que no ha existido intervención hay que detener el examen pues, estando ante una cuestión de derechos fundamentales, no se trata de una cuestión de limitación de los mismos. Si, por el contrario, se estima que sí ha existido intervención en el ámbito normativo del derecho se pasa a la tercera fase, de justificación o examen de la legitimidad de las restricciones a los derechos fundamentales. Es importante destacar que el método escalonado también se aplica dentro de esta tercera fase, de tal forma que lo que hay que analizar es que se respeten todos y cada uno de los requisitos que la Constitución (o el CEDH o el Derecho Comunitario, en su caso) exige para que una intervención en un derecho fundamental sea legítima. Deben así analizarse cada uno de estos requisitos uno por uno y si en algún momento se llega.a la conclusión de que alguno no se ha respetado, el examen deberá detenerse, declarando la inconstitucionalidad de la intervención sin más trámites. Y es que es claro que lo que la Constitución exige no es que la intervención en el derecho fundamental respete la reserva de ley o que respete el principio de proporcionalidad (en cada uno de sus subprincipios: adecuación, necesidad y proporcionalidad en sentido estricto) $o$ el contenido esencial, etc., sino que lo que exige. es que respete todos y cada uno de esos requisitos, cumulativa y no alternativamente, de manera que, si uno solo de ellos no se respeta, la medida no puede pretenderse constitucionalmente legítima.

7. Se trata de definir el contenido prima facie, antes de toda limitación, del derecho fundamental, para lo que deberá atenderse fundamentalmente a su objeto o bien jurídico protegido y que habrá de definirse de manera diferenciada, como es natural, para cada derecho fundamental. Aquí se distingue, en términos generales, según se siga una concepción amplia o una estrecha del ámbito normativo. Los partidarios de las concepciones estrechas tienden a resolver como cuestiones ajenas al derecho fundamental las que los partidarios de una concepción amplia (o más amplia, al menos) del "tipo" o ámbito normativo consideran que sólo cabe resolver en términos de derechos fundamentales y con aplicación de las garantías constitucionalmente previstas para las hipótesis en que se trata de limitar un derecho fundamental; excluyen ya de entrada de la cobertura del "tipo" o ámbito normativo del derecho fundamental, mediante su exacta delimitación, determinadas posiciones, mientras que los partidarios de una concepción amplia incluyen de entrada esas posiciones en el ámbito normativo o tipo del derecho y, sólo si resulta constitucionalmente justificado, admiten una restricción al respecto, con la correspondiente aplicación de las garantías constitucionales (reserva de ley, principio de proporcionalidad, etc). Como se comprenderá, tiene una gran relevancia seguir una concepción amplia o una concepción estrecha del ámbito normativo o tipo de los derechos fundamentales o de uno de ellos en particular, pues los partidarios de las. segundas tienden a excluir la aplicación de las garantías constitucionales a muchos supuestos que consideran que hay que excluir, ya de entrada, de la cobertura del derecho fundamental en una precisa delimitación de su contenido, mientras que los partidarios de una concepciọn amplia exigirán la aplicación también a tales supuestos de las mencionadas garantías para que una restricción pueda considerarse legítima. Por ejemplo, si el Estado prohíbe a un ciudadano pintar en una vía públiça, un partidario de una concepción estrecha podrá considerar que no hay ninguna cuestión de derechos fundamentales, pues la libertad artística no se extiende, ya de entrada, a la actividad de pintar "en una vía pública", mientras que el partidario de una concepción amplia del ámbito normativo de esta libertad, considerará, por el contrario, que la libertad fundamental sí es de aplicación a ese caso y que la prohibición, como intervención que es en dicha libertad, sólo será legítima si respeta la reserva de ley, la ley que la fija o permite es general, obedece a un fin constitucional y observa los mandatos de la proporcionalidad, etc., exigencias todas ellas que no regirían para el partidario de una concepción estrecha. Por supuesto, 
injerencia en el derecho fundamental ${ }^{8}$; c) Justificación constitucional9 (o conforme al CEDH, en su caso).

Este método responde, en realidad, en gran medida, si bien se piensa, a la naturaleza de las cosas y ello explica acaso que haya sido aceptado también en Austria, Suiza y Liechtenstein y pueda hoy decirse, sin hipérbole, que es un método "germánico", y no sólo alemán, de análisis de las cuestiones relativas a los derechos fundamentales y sus límites. Es más, el método se ha extendido, o va extendiéndose, también a otros países fuera del área germánica de influencia, especialmente europeos, entre los que se cuenta España, en especial a partir de las SSTC 55/1996 y 66/1995, si bien su aplicación se ha hecho, en ocasiones, un tanto "a ciegas". A ello ha contribuido también la aceptación creciente que ha tenido este método en la jurisprudencia tanto del Tribunal de Estrasburgo como en la del Tribunal de Luxemburgo y lo de cerca que estos Tribunales han seguido, por razones que no son del caso pero entre las que destaca su elevado rigor y practicabilidad y posibilidad de control intersubjetivo, la jurisprudencia del TCFA que lo aplica.

Pues bien, este método será el que se siga en la siguiente exposición de la doctrina de las dos sentencias objeto de este comentario, lo que permitirá, desde nuestro punto de vista, un análisis estricto, sistemático y contrastado de las dos sentencias y poner de relieve algunas de las cuestiones constitucionales que las mismas, o la reflexión jurídica en torno a ellas, han venido a plantear, así como las posibles soluciones al problema concreto de fondo que han tenido que resolver y que será objeto creciente de preocupación en nuestras sociedades: la integración de extranjeros con creencias religiosas diversas a las predominantes en nuestras sociedades y, en concreto, la forma más adecuada para ello, en términos de derechos fundamentales, respecto a la necesidad de sacrificar ritualmente animales sin anestesia frente a la exigencia general de anestesiarlos previamente. Pero también permitirá poner de relieve, a partir

que cabe una gradación y, más que una concepción amplia o estrecha en abstracto, se trata de determinar si se sigue una concepción más o menos amplia o más o menos estrecha respecto del ámbito normativo de cada derecho fundamental. Al respecto, puede decirse que en la doctrina alemana la mayoría de los autores siguen, globalmente, una concepción amplia del ámbito normativo del derecho fundamental y también lo hace así la jurisprudencia del TCFA, al menos en términos generales.

8. Hay que analizar si existe una acción u omisión susceptible de ser considerada una afectación, injerencia o incidencia restrictiva en el derecho fundamental. Por razones obvias, los partidarios de las concepciones amplias del ámbito normativo del derecho fundamental tenderán a defender un correlativamente amplio concepto de intervención, mientras que los partidarios de una concepción estrecha tenderán a seguir un concepto más estrecho de intervención, pues los primeros tenderán a resolver como cuestiones de (límites a los) derechos fundamentales las que los otros resolverán ya de entrada con una delimitación del ámbito normativo del derecho fundamental, excluyendo ya "a priori" de la cobertura del derecho a determinadas hipótesis.

9. Debe aquí examinarse si la intervención en el derecho fundamental cumple los requisitos exigibles a partir de la Constitución o el CEDH para las restricciones a los derechos fundamentales: por ejemplo, reserva de ley, principio de proporcionalidad (con sus tres subprincipios de idoneidad, necesidad y proporcionalidad stricto sensu), contenido esencial, etc. 
del caso concreto, alguna cuestión central de la dogmática relativa a los derechos fundamentales, aparte ya la conveniencia misma de utilizar con rigor un método sistemático de examen: la importancia de seguir una concepción amplia tanto del ámbito normativo o "tipo" de los derechos fundamentales como del concepto de "intervención", "injerencia" o "interferencia" en los derechos fundamentales. A esto último sólo dedicaremos aquí unas reflexiones finales.

\section{EL ÁMBITO NORMATIVO DE LOS DERECHOS FUNDAMENTALES AFECTADOS}

La primera, y fundamental, cuestión que se plantea en las dos sentencias estudiadas es la de si la libertad religiosa (pero también, junto a ella, la libertad de profesión en el caso estudiado por el TCFA) comprende la pretensión, basada en creencias religiosas, de determinados ciudadanos extranjeros pertenecientes a una corriente minoritaria de una religión para obtener una autorización excepcional para llevar a la práctica el "sacrificio" ritual de animales, esto es, la muerte de los mismos sin previa anestesia. Pero el caso resuelto por el TCFA y el planteado ante el TEDH presentan también, a partir de esta problemática común, notables diferencias. Así se ve ya al analizar el ámbito normativo de los derechos fundamentales afectados en cada caso. Véamos la cuestión en cada caso por separado.

a) Caso (alemán) del "carnicero turco": En primer lugar, en el caso a decidir por el TCFA, hay que tomar en cuenta una serie de datos: de un lado, el artículo 4 a de la Ley de Protección de Animales establecía que no cabe matar a animales de sangre caliente si no están anestesiados desde que comienza a fluir la sangre, si bien no se necesitará la anestesia cuando las autoridades den una autorización excepcional para atender a las necesidades de los miembros de determinadas comunidades religiosas cuyos preceptos imperativos prescriban la muerte sin anestesia (en adelante, art. 4a.2.1) o prohíban el consumo de carne de animales no sacrificados (en adelante, art. 4a.2.2); de otro lado, no puede dejar de tenerse en cuenta que el sacrificio ritual posee, en Alemania, una significación histórica singular, pues si bien el mismo se permitía a los judíos de manera excepcional a principios del siglo pasado, una vez que los nazis ascendieron al poder se produjo una prohibición progresiva de tales sacrificios por los distintos Länder, hasta que, en 1933, a fin de infligir otro "pequeño" daño más a las tradiciones y sentimientos religiosos de la comunidad judía, se aprobó la Ley sobre matanza de animales, que prohibía tal sacrificio. Al terminar la Segunda Guerra Mundial, y ser derrocado el régimen nazi, se toleró - bien tácitamente, bien de forma expresa - el sacrificio ritual de animales y no fue hasta 1986 cuando se aprobó una disposición legal a escala federal sobre la cuestión, que es el artículo 4 a.

En el caso concreto, se trataba de un carnicero musulmán extranjero, turco concretamente, que solicitaba una autorización para practicar esos sacri- 
ficios rituales conforme a lo que entendía que le exigía su religión, lo que le fue denegado. El derecho fundamental primordialmente afectado va a ser, para el TCFA, la libertad de acción del artículo 2 LF en cuanto que abarca a la libertad de profesión de los extranjeros ${ }^{10}$, pero también la libertad religiosa. Es evidente, en este sentido, dirá el TCFA, que la negativa por las autoridades administrativas, luego confirmada por los tribunales, a dar una autorización excepcional al carnicero musulmán para sacrificar a los animales sin anestesia $\mathrm{y}$, así, ofrecer esa carne a sus clientes que, por razones religiosas, le demandaban ese tipo de carne, afecta a la libertad de profesión como carnicero del solicitante de amparo, que, al tratarse de un nacional turco y no alemán, encuentra amparo por la vía de la libertad general de acción, como derecho fundamental residual, en virtud de sú relación de especialidad con el artículo 12 LF. Ahora bien, dice el TCFA, el sacrificio no es sólo medio para el afectado para obtener y preparar carne para sí mismo y sus clientes musulmanes, sino que es, además, expresión de una postura religiosa fundamental por su parte, que para él, como musulmán sunita practicante, resulta vinculante. Así pues, hay que tomar en cuenta, también si el sacrificio mismo no se considera un acto de ejercicio de la religión, que la protección de la libertad de profesión a partir del artículo $2.1 \mathrm{LF}$ es reforzada, en este caso, por virtud del contenido especial de libertad del derecho fundamental a la libertad religiosa del artículo $4 \mathrm{LF}$.

En definitiva, hay que interpretar, desde nuestro punto de vista, que el TCFA considera que se produce una concurrencia de derechos fundamentales (libertad de acción como tuteladora de la libertad de profesión de un extranjero y libertad religiosa como elemento que refuerza a la primera, al menos en cuanto a su "contenido de libertad"), pero el examen se hará atendiendo, sobre todo, al del artículo $2.1 \mathrm{LF}$ ( en su específica modalidad de libertad de profesión de los extranjeros) como derecho fundamental primordialmente afectado, aunque se considerará reforzado éste por el hecho de amparar también prima facie la libertad religiosa la actividad para la que se busca tutela iusfundamental.

En cuanto al principio de igualdad y la prohibición de discriminación, alegados también en la causa por los recurrentes por ser discriminatoria la regulación legal aplicable (respecto de la autorización excepcional a la matanza sin anestesia), el TCFA, tras el análisis de la posible vulneración de los derechos a la libertad profesional y a la libertad religiosa, considerará que no existe ninguna desigualdad posible que haya que controlar, pues, al menos en la interpretación secundum constitutionem que el TCFA realizará, como luego vere-

10. La LF protege en su artículo 12 la libertad de profesión como uno de los llamados «derechos fundamentales alemanes", esto es, cuya titularidad se reconoce sólo a los alemanes, pero el TCFA ha interpretado la libertad (residual) general de acción, consagrada como derecho fundamental en el artículo 2 LF, en un sentido tal que ampara también la libertad de profesión de los extranjeros no cubiertos por el derecho del artículo $12 \mathrm{LF}$, si bien su libertad se sujeta, por ello mismo, a unos límites constitucionales de más amplio alcance. 
mos, de los preceptos legales aplicables, no se produce ningún trato discriminatorio entre musulmanes y judíos, por lo que no se entra ya a analizar a fondo una posible discriminación, que simplemente no existe.

b) Caso "Asociación judía ultraortodoxa minoritaria": En el caso a examinar por el TEDH, las circunstancias eran distintas, pues se referían a la denegación por parte del Gobierno francés de una autorización administrativa especial solicitada por una asociación religiosa judía de carácter ultraortodoxo para acceder a las instalaciones de los mataderos autorizados y efectuar sacrificios rituales de animales conforme a los preceptos religiosos de esa corriente judía ultraortodoxa minoritaria, que eran más exigentes y rigoristas - a fin de asegurar la pureza de la carne de los animales sacrificados- en el procedimiento de matanza que los de la asociación judía mayoritaria, a la que sí se había autorizado ya por el Gobierno a la práctica del sacrificio ritual sin anestesia.

En concreto, exigían estos fieles judíos ultraortodoxos un control más exhaustivo de la sangre que pudiera haber en los pulmones de los animales. Los miembros de dicha asociación, recurrente ante el TEDH, entendían que los métodos empleados por la entidad religiosa judía mayoritaria, en virtud de la correspondiente autorización especial administrativa, no eran conformes con la ortodoxia judía más tradicional, por lo que la denegación del permiso para realizar tales prácticas por sí misma constituiría una vulneración de su derecho a manifestar las propias convicciones religiosas a través de la uobservancia" de sus ritos sagrados.

El TEDH se plantea, en primer lugar, si los derechos fundamentales alegados por la asociación demandante (libertad religiosa y principio de interdicción de la discriminación en el ejercicio de dicha libertad) resultan aplicables, algo que el Tribunal de Estrasburgo analiza, a diferencia del TCFA, de modo conjunto, lo que se explica por el hecho de que la discriminación prohibida por el CEDH lo es respecto al ejercicio de algún derecho fundamental (la libertad religiosa, en este caso); y, por otro lado, a diferencia también del Tribunal alemán, no se refiere el Tribunal Europeo a la libertad de profesión, dado que ésta no aparece gạrantizada por el Convenio ni la alegación de derechos fundamentales se refiere al ejercicio de la profesión de carnicero por parte de alguno de sus asociados.

Pues bien, sostiene el TEDH que la libertad religiosa y la prohibición de discriminación son aplicables en este caso, como nadie puso en duda en el proceso (ni siquiera lo hizo así el Gobierno francés, pese a insistir en que la asociación tenía un fin fundamentalmente económico), y ello por cuanto que entiende el Tribunal de Estrasburgo que, de un lado, un órgano religioso o eclesiástico puede ejercitar la libertad religiosa en nombre de sus adherentes y tal libertad comprende, entre otras actividades, según dice expresamente el artículo $9 \mathrm{CEDH}$, el culto, la enseñanza, la práctica y la observancia de la propia religión; y, de otro lado, el sacrificio ritual de animales constituye un "rito", como su propio nombre indica (téngase presente que "rite" en la versión fran- 
cesa se corresponde al término castellano "observancia"), cuyo propósito es proveer a los judíos de carne de animales sacrificados conforme a los preceptos religiosos, lo que es un aspecto esencial de la práctica de la religión judía. Y, en este caso, la asociación en cuestión emplea a matadores rituales propios e inspectores de kashrut que sacrifican animales de acuerdo con sus prescripciones al respecto y es igualmente tal asociación la que, al certificar la pureza, según sus prescripciones morales, de la carne vendida en las carnicerías de sus miembros, ejercita la supervisión religiosa del sacrificio ritual. Dicho en pocas palabras, "el sacrificio ritual debe considerarse cubierto por un derecho garantizado por la Convención", cual es el derecho a manifestar su propia religión en la "observancia" de la misma con el significado del artículo $9 \mathrm{CEDH}$ (parágrafos 73 y 74).

\section{INTERVENCIÓN EN EL DERECHO FUNDAMENTAL}

Una vez determinado qué derecho fundamental o derechos fundamentales son de aplicación al caso sujeto a examen (en el caso resuelto por el TCFA: derecho a la igualdad, por un lado, y libertad de acción en su modalidad de libertad de profesión de extranjeros y libertad religiosa, por otro lado; y en el caso resuelto por el TEDH: libertad religiosa e igualdad), es preciso averiguar si, además, se ha producido "in casu" una actuación de un poder público que pueda considerarse que "interviene" en tal derecho o derechos, afectándolos de un modo restrictivo.

a) El caso "carnicero turco": En lo que se refiere a este asunto resuelto por el TCFA, debe empezar por decirse que el Tribunal Federal Administrativo (TFA), al resolver la cuestión en su Sentencia de 15 de junio de 1995 (BVerwGE 99, 1), había entendido que la negativa a una autorización excepcional al sacrificio sin anestesia de animales no conllevaba una intervención en tal libertad cuando las convicciones religiosas de los afectados sólo les prohibían el consumo de carne de animales sacrificados con anestesia, pues no se les prohibía, con ello, una conformación de su vida con arreglo a sus convicciones, ya que no se les obligaba, ni jurídica ni fácticamente, al consumo de carne de animales que no hubiesen sido sacrificados según sus propias convicciones religiosas, y podían, además, comer alimentos vegetarianos, pescado o, incluso, carne importada de animales que hubiesen sido sacrificados conforme a sus propias convicciones ${ }^{11}$.

11. Como señala Christine Langenfeld ("Germany", cit., p. 143), a raíz de esta sentencia del TFA, las autoridades alemanas, en contra de lo que había venido siendo la práctica habitual hasta entonces, denegaron en general todas las autorizaciones excepcionales de matanza ritual de animales, mientras que las mismas sí que seguían concediéndose a los carniceros judíos. Las autoridades entendían que la autorización excepcional sólo podía otorgarse a miembros de asociaciones religiosas cuyas normas imperativas $y$, especialmente, indiscutidas exigieran una matanza ritual y, a diferencia de lo que ocurre con la comunidad judia, dentro del Islam hay grupos que 
Pues bien, frente a esta interpretación, ciertamente cuestionable, el TCFA va a partir de que ha habido una intervención en la libertad de profesión y la libertad religiosa, que habría consistido en la denegación por las autoridades administrativas, luego confirmada por los tribunales, de una autorización excepcional para matar animales sin previa anestesia (en contra de la regla general prohibitiva del sacrificio sin anestesia de animales de sangre caliente). Esa medida adoptada por un poder público es una intervención en el derecho fundamental que conlleva una restricción de las posibilidades de actuación "prima facie" otorgadas por la libertad religiosa y la libertad profesional. Estamos, pues, ante una intervención en dichos derechos fundamentales, siendo cuestión distinta la de la intensidad de tal intervención, que habrá que valorar en una fase ulterior, como luego se verá.

B) Caso "Asociación judía ultraortodoxa minoritaria": En este caso, el TEDH va a considerar, por el contrario, que no existió una "intervención" o, utilizando su propia terminología, una uinjerencia" en la libertad religiosa, siguiendo así el criterio defendido por el Gobierno francés, y ello hizo innecesario entrar ya a analizar la compatibilidad con el Convenio de tal interferencia, que se concluye por el Tribunal que no ha existido en el caso sub judice. El TEDH considera, concretamente, que la regulación legal francesa por la que se establece una excepción al principio de que los animales deben ser anestesiados antes de ser sacrificados «lejos de restringir el ejercicio de esa libertad [de religión], está prevista, por el contrario, para atender a las necesidades de su libre ejercicio y organizar éste, asegurando así el respeto efectivo de tal libertad". Y es que resulta de interés general evitar un sacrificio desregulado, ejecutado en condiciones de dudosa higiene y es preferible que, si tiene que haber un sacrificio ritual, sea ejecutado en mataderos supervisados por las autoridades públicas. «De acuerdo con ello, cuando en 1982 el Estado concedió aprobación a la ACIP, una ramificación del Consistorio central, que es el cuerpo más representativo de las comunidades judías en Francia, no infringió en modo alguno la libertad de manifestar la propia religión" (parágrafo 77).

Sin embargo, dice el Tribunal, cuando otra corporación religiosa que profesa la misma religión solicita una autorización para llevar a cabo un sacrificio ritual, "debe averiguarse si el método de sacrificio que pretende utilizar constituye o no ejercicio de la libertad de manifestar la propia religión garantizado por el artículo 9 del Convenio" (parágrafo 78). Y aquí el Tribunal concluye que el método empleado por la asociación recurrente es "exactamente el

discuten el carácter imperativo de la regla sobre matanza ritual de animales, por lo que no se daban los presupuestos para la aplicación del artículo 4a.2.2 de la Ley de Matanza de Animales, antes citado (de hecho, muchas comunidades islámicas están dispuestas a adoptar, y algunas incluso lo practican ya, el atronamiento de los bovinos y de los pequeños rumiantes utilizando métodos eléctricos antes de cortar la garganta y de proceder ál desangrado). De ahí que el recurrente en amparo también alegase el principio de igualdad en su demanda, por más que, como luego se verá, a la postre esa alegación no tuviera relevancia constitucional. 
mismo" que el empleado por la asociación mayoritaria ya autorizada y que "la única diferencia reside en la exhaustividad del examen de los pulmones del animal sacrificado después de la muerte. Es esencial para la asociación demandante poder certificar que la carne no es sólo autorizada por la ley judía (kosber), sino también que es glatt a fin de cumplir con su interpretación de las leyes dietéticas, mientras que la inmensa mayoría de los judíos practicantes acepta la certificación kosher expedida bajo la tutela" de la asociación mayoritaria" (parágrafo 79).

Y considera el TEDH que "habría una interferencia en la libertad religiosa sólo si la ilegalidad de ejecutar sacrificios rituales hiciera imposible a los judíos ultraortodoxos comer carne de animales sacrificados de acuerdo con los preceptos religiosos que ellos considerasen aplicables", "pero éste no es el caso. No se discute que la asociación demandante puede fácilmente obtener suministros de carne glatt en Bélgica", además de que de la prueba documental se deduce de forma evidente que «una serie de las carnicerías que operan bajo el control de la ACIP permiten disponer a los judíos de carne certificada como glatt por el Beth Din" (tribunal rabínico que regula lo relativo al Derecho religioso -matrimonio, divorcio y conversiones-, supervisa la observancia de las leyes dietéticas y elige y controla a los mataderos e inspectors kashrut empleados por el Consistorio judío).

En efecto, del conjunto de la instrucción y de los testimonios orales se deduce para el Tribunal que los judios que pertenecen a la asociación demandante pueden, así, obtener carne glatt. "En particular, el Gobierno se refirió, sin ser contradicho en este punto, a negociaciones entre la demandante y la ACIP a fin de lograr un acuerdo por virtud del cual aquélla pudiera llevar a cabo sacrificios rituales ella misma bajo la cobertura de la aprobación concedida a la ACIP, un acuerdo que no se alcanzó por razones económicas (parágrafo 67)". $\mathrm{Y}$, dice el TEDH, si bien es cierto que la asociación recurrente manifestó que no confiaba en los sacrificios rituales autorizados por la ACIP en lo relativo a la exhaustividad del examen de los pulmones de los animales tras el sacrificio, a juicio del Tribunal, la libertad religiosa "no puede extenderse al derecho a tomar parte en persona en la ejecución del sacrificio ritual y al subsiguiente proceso de certificación" y ello por entender que no se priva ni a la asociación ni a sus miembros de la posibilidad de obtener y comer carne que consideren más compatible con los preceptos religiosos (parágrafo 82). Y al no probarse que los judíos de la asociación demandante no pudiesen obtener carne "glatt" ni que el demandante no pudiese suministrársela alcanzando un acuerdo con la ACIP a fin de poder dedicarse al sacrificio ritual bajo la cobertura de la autorización concedida a la ACIP, «el Tribunal considera que la negativa a la aprobación impugnada no constituyó una interferencia en el derecho de la asociación demandante a la libertad de manifestar su religión" (parágrafo 83).

Frente a este entendimiento de la mayoría del Tribunal, y con toda razón desde nuestro punto de vista, siete magistrados del TEDH formularon un voto particular conjunto (joint dissenting opinion) a la sentencia en el que, entre 
otras cosas, consideraron errada la conclusión alcanzada por la mayoría de que no había habido una injerencia en la libertad religiosa y el principio de igualdad, por considerar que si bien la concesión, en su día, a la ACIP del correspondiente permiso no puede considerarse como restricción, sino como cumplimiento efectivo de la libertad religiosa, ello no justifica considerar que no sea una interferencia o intervención en la libertad religiosa, con relación a la interdicción de discriminación en su ejercicio, la negativa a conceder otra autorización a una corriente minoritaria diversa dentro de la propia religión para llevar a cabo sus propios sacrificios rituales por no existir acuerdo con la corriente mayoritaria en el modo de llevar a cabo ese sacrificio ${ }^{12}$, en concreto en la exhaustividad del examen de la sangre que pueda quedar en los pulmones de los animales tras su sacrificio. Dice la minoría disidente que aunque con una nueva autorización puede promoverse la tensión y la división religiosa, no es tarea del Estado evitarlo a costa de dejar de respetar (o eliminar) el pluralismo, sino que ha de limitarse aquél a asegurar la necesaria tolerancia de unos grupos religiosos respecto de otros.

Y desde luego, no comparten los magistrados disidentes la referencia a que la asociación demandante pudo llegar a un acuerdo con la ACIP para el sacrificio, aprovechando, así, la autorización de que gozaba esta última, pues precisamente lo que caracteriza a la asociación demandante es su discrepancia con la ACIP en cuanto al modo de ejecutar los sacrificios de animales y la ACIP, como comunidad judía mayoritaria, es justamente la que está peor situada para decidir sobre la validez de las demandas de la asociación demandante minoritaria y actuar como árbitro al respecto, por lo que no dudan en tachar de inapropiada dicha argumentación de la mayoría del Tribunal. Y estiman, también, que es indiferente que los miembros de la asociación demandante puedan adquirir carne de animales sacrificados conforme a sus reglas por otros medios, estimando que ello no obsta a reconocer, en contra de lo que sostuvo la mayoría del Tribunal, que ha habido una injerencia estatal en el ejercicio de la libertad religiosa (esto es, un acto u omisión por parte del Estado restrictivo de un derecho fundamental).

\section{JUSTIFICACIÓN CONFORME A LA LF O CONFORME AL CEDH}

En primer lugar, debe averiguarse si la intervención afectante a la actividad que se ha determinado que está prima facie amparada por el ámbito normativo o "tipo" del derecho fundamental de que se trate resulta justificada conforme al CEDH o a la Ley Fundamental de Bonn.

12. Dicen los magistrados disidentes: “El mero hecho de que se haya concedido ya la aprobación a un organismo religioso no exime a las autoridades estatales de su obligación de prestar una consideración cuidadosa a cualquier otra solicitud ulterior hecha por otros organismos religiosos que profesan la misma religión". 
Esta fase de examen no la llevó a cabo ya el TEDH por considerar que no había habido en el caso por él enjuiciado una injerencia (o intervención) en la libertad religiosa, por lo que, no habiendo injerencia en ningún derecho fundamental, el examen de la justificación conforme al Convenio quedaba sin objeto posible.

En lo que se refiere, en cambio, al caso alemán ("carnicero turco musulmán"), sí que se llevó a cabo, en cambio, este examen. Debe partirse, al respecto, de que, como es sabido, ningún derecho fundamental es absoluto, pero tampoco lo son, menos todavía, los límites a que cabe someter un derecho fundamental. En el caso de la libertad general de acción, este mismo precepto somete a tal derecho a una tríada de límites: el orden constitucional (interpretado por la jurisprudencia constitucional, en un sentido amplísimo, como inclusivo de todas las normas del ordenamiento jurídico formal y materialmente conformes con la Constitución); la ley moral; y los derechos de los demás. Y la libertad religiosa, por su parte, se somete al límite implícito de la protección de otros bienes o derechos constitucionales colisionantes de superior rango (BVerfG $N J W$ 1999, 3403). Ahora bien, la apreciación de que la intervención en los derechos fundamentales en cuestión está justificada exige llevar a cabo un examen por fases más complejo, en el que hay que constatar que se han respetado los siguientes aspectos: 1.- Reserva de ley; 2.- Generalidad de la ley; 3.- Mandato de cita; 4.- Proporcionalidad. A ello pasamos a referirnos.

\section{RESERVA DE LEY}

Este requisito se cumplía, pues la intervención en el derecho fundamental ya comentada aparecía cubierta por una ley formal, en concreto la Ley de Protección de Animales vigente en el momento a que se refieren los hechos, cuyo artículo 4 establecía, entre otras cosas, lo que sigue:

"1. Un animal de sangre caliente sólo puede ser sacrificado si ha sido anestesiado previamente al comienzo del flujo de la sangre.

2. Como excepción a lo establecido en el apartado primero, no se necesita una anestesia cuando

1. [...]

2. la autoridad competente haya concedido una autorización excepcional para un sacrificio sin anestesia; podrá conceder la autorización excepcional cuando sea necesaria para atender las necesidades de los miembros de determinadas comunidades religiosas en el ámbito de validez de esta ley a los que preceptos obligatorios de su comunidad religiosa prescriban el sacrificio o prohíban el consumo de carne de animales no sacrificados". En cuanto a la doctrina de la esencialidad que rige respecto de la reserva de ley, debe recordarse que la misma exige que el legislador "debe adoptar por sí mismo todas las decisiones esenciales en los ámbitos normativos bási- 
cos, especialmente en el marco del ejercicio de los derechos fundamentales, en cuanto esta regulación estatal sea alcanzable ${ }^{13}$, también en la medida en que esas cuestiones "esenciales" no constituyan intervenciones, y no puede el legislador delegar tales decisiones en la Administración. Esta teoría puede considerarse respetada en este caso, por cuanto que la intervención en sí misma, sus presupuestos y alcance aparecían previstos en la Ley con suficiente determinación con relación al caso de que se trataba.

\section{GENERALIDAD DE LA LEY}

Aunque el TCFA no se pronuncia expresamente respecto a la generalidad de la ley, pues nadie puso en duda que se respetaba en este caso este requisito, debe afirmarse expresamente que concurría, en efecto, en este caso, pues la norma antes citada no va dirigida, ni de forma explícita ni de forma indirecta o encubierta, a un caso particular, sino que se formula en términos generales y abstractos y es susceptible de aplicación a una pluralidad diversa de supuestos.

\section{MANDATO DE CITA}

El mandato de cita exige que la ley limitativa de un derecho fundamental cite el concreto derecho fundamental restringido, a fin de que el legislador sea siempre consciente de que está restringiendo dicho derecho (Warnfunktion, función de advertencia). Lo importante es que en la interpretación dada por el TCFA a esta garantía, su alcance aparece muy restringido y, en particular, no regiría en este caso, a la vista de los derechos fundamentales afectados (no se aplica ni a la libertad de acción: BVerfGE 10, 99; ni a la de profesión: BVerfGE 64, 72, 79; ni a las libertades, como la religiosa, sin reserva expresa de ley: BVerfGE 83, 130, 154). Y por ello mismo, tampoco desde esta perspectiva, puede formularse reproche jurídico-constitucional alguno a la medida en cuestión afectante de los derechos de libertad de profesión de extranjeros (protegida por la libertad de acción) y de libertad religiosa.

\section{PRINCIPIO DE PROPORCIONALIDAD}

$\mathrm{Si}$ los anteriores requisitos constitucionales han sido respetados en este caso según la interpretación del TCFA, mayores problemas plantea determinar si ha resultado también observado el principio de proporcionalidad. El TCFA va a analizar si se ha respetado este principio con una perspectiva abstracto- 
concreta, referida, pues, tanto a la Ley en abstracto, como a su interpretación y aplicación concretas por los jueces en el caso particular de que se trataba.

\section{A) Fin legítimo}

En primer lugar, el TCFA va a averiguar cuál es el fin que persigue la regulación que autoriza la intervención en el derecho fundamental sujeta a su control, para luego determinar si tal finalidad puede considerarse constitucionalmente legítima para restringir el derecho fundamental de que se trata. $Y$ dirá el Tribunal que el fin, éticamente fundado, de la regulación legal, es la tutela de la vida y bienestar de los animales, a los que no se considera como cosas, sino como otras criaturas dotadas de vida y una concreción, en el particular aspecto de la matanza de los animales de sangre caliente, de la concepción más general, que inspira la Ley de Protección de Animales, de que hay que evitar a estos últimos todo dolor, sufrimiento o daño que no tenga una fundamentación razonable. Ello, dirá el TCFA, es un legítimo objetivo de la regulación, que responde al sentimiento de amplias capas de la población ${ }^{14}$.

\section{B) Adecuación y necesidad}

El control del TCFA sobre la adecuación se va a producir de forma inseparablemente ligada al control de la necesidad, por más que el contenido de ambos subprincipios de la proporcionalidad sea bien distinto. Sin embargo, el TCFA va a incidir, sobre todo, en la prerrogativa de decisión de que goza el legislador a la hora de elegir los medios que resulten más adecuados y necesarios para lograr el fin concreto pretendido con la regulación de que se trate, y sobre esa base, común a ambos subprincipios, analizará la adecuación y necesidad de la medida sujeta a examen conjuntamente.

A juicio del TCFA, la Constitución concede al legislador, a la hora de enjuiciar la adecuación y necesidad de los medios por él elegidos para llevar a cabo los objetivos de la legislación, un campo de juego para la evaluación y ello rige también respecto a los fundamentos fácticos de una regulación legislativa, sin que pueda presumirse una estimación o evaluación errada al respecto.

14. Se ha discutido mucho en la doctrina alemana si la protección de los animales es un fin constitucional que puede autorizar una restricción de derechos fundamentales. Véase, sobre ello, BVerfGE 101,1. La cuestión sigue siendo discutida aun después de la reciente reforma constitucional, de 26 de julio de 2002, que introdujo la tutela de los animales en el artículo 20a LF como objetivo de Estado [Gesetz zur Änderung des Grundgesetzes (Staatsziel Tierschutz)]. Ahora el artículo 20a de la LF reza: "El Estado, teniendo en cuenta su responsabilidad con las generaciones futuras, protegerá, dentro del marco del orden constitucional, los fundamentos naturales de la vida y a los animales a través de la legislación y, de acuerdo con la ley y el Derecho, por medio de los poderes ejecutivo y judicial" (cursiva nuestra). 
En el caso concreto sujeto a examen, el Tribunal, a la vista de lo anterior, concluye que la regulación legal es conforme al subprincipio de adecuación, pues precisa que, si bien hay quienes dudan que el sacrificio de los animales con anestesia previa produzca claramente menos dolores y sufrimientos al animal que su matanza sin anestesia (y a título de ejemplo, remite el Tribunal, respecto de las ovejas y terneros, a la ponencia panorámica de Schulze/SchultzePetzold/Hazem/Groß, Deutsche Tierärztliche Wochenschrift, núm. 85,1978, S. $62 \mathrm{ff}$.), ello no parece todavía aclarado científicamente de forma definitiva y así, otros, como la Liga alemana protectora de animales en la correspondiente audiencia ante el TC, se decantan claramente por la muerte con anestesia y también el artículo 12 de la Convención Europea para la Protección de los Animales de Sacrificio de 10 de mayo de 1979 y el artículo 5.1.c) de la Directiva 93/119 del Consejo de la Unión Europea, de 22 de diciembre de 1993, relativa a la protección de los animales en el momento de su sacrificio o matanza, parten de que se ocasionan menores dolores y sufrimientos a los animales cuando se los anestesia antes de matarlos.

La evaluación del legislador que se ajusta a ello y su aceptación de que el mandato de anestesia, consagrado por la Ley, es adecuado y - a falta de una alternativa igualmente efectiva - también necesario para lograr el fin pretendido por dicha ley (artículo 1) es, cuando menos, a la vista de todo lo anterior, sustentable. Y lo mismo vale, según el TCFA, para la regulación excepcional del artículo 4a de la Ley de protección de animales cuando permite la exoneración del deber de anestesiar a los animales con carácter previo a su sacrificio y la sujeta a una autorización excepcional, pues ha querido el legislador someter al sacrificio sin anestesia a un control estatal reforzado.

En especial, debió crearse la posibilidad, más allá del examen de los conocimientos profesionales y de la adecuación personal de las personas que lo demandaban, de garantizar, por medio de disposiciones complementarias a la autorización excepcional, que se ahorrasen a los animales que hubieran de ser sacrificados todos los dolores o sufrimientos evitables en su transporte, en su tranquilidad y en el propio proceso de sacrificio (sin anestesia), lo que pudo lograrse, por ejemplo, con reglamentaciones sobre los espacios, instituciones y demás medios de ayuda que resulten adecuados. En la medida de lo posible, deben prohibirse los sacrificios caseros o, más en general, privados, pues respecto de ellos frecuentemente no puede asegurarse un sacrificio acorde con las reglamentaciones, con el consiguiente sufrimiento de los animales $y$, en lugar de ello, esforzarse por que los sacrificios se hagan en mataderos autorizados.

Por lo demás, la concesión de la autorización excepcional al sacrificio sin anestesia previsto en el artículo 4 a de la Ley presupone que tiene que darse una necesidad de los miembros de una comunidad religiosa cuyos preceptos obligatorios prohíban el consumo de carne de animales no sacrificados sin anestesia. Al admitir la Ley excepciones del mandato de anestesia sólo bajo estos presupuestos, el número de excepciones a tomar en consideración se 
reduce irremediablemente. En el caso de una religión como el Islam, ocurre que este mismo, según ha manifestado el propio Consejo central de los musulmanes en Alemania en su toma de postura, exige una matanza de los animales lo más dulce posible, de forma que el sacrificio del animal debe realizarse tan rápidamente como sea posible y su sufrimiento debe limitarse a un mínimo, evitándosele todo tipo de tormento. También por ello, concluye el TCFA podía partir el legislador de que la reserva a la excepción del artículo 4 a representa una medida adecuada, y también necesaria, a fin de garantizar una protección de los animales vinculante por mandatos éticos.

\section{C) Proporcionalidad en sentido estricto}

El TCFA lleva a cabo aquí una ponderación conjunta de la gravedad de la intervención en el derecho fundamental (autorización sólo excepcional para matar animales de sangre caliente sin anestesia), por un lado; y, de otro lado, el peso y la urgencia de las razones que exigen tal intervención.

En cuanto a lo primero, afirma el TCFA, en primer lugar, que la intervención en la libertad de profesión del carnicero tiene un peso considerable, pues sin esa autorización excepcional no sería posible ya para los musulmanes creyentes, como el solicitante de amparo, ejercer la profesión de carnicero, debiendo limitarse a vender carne importada sacrificada sin anestesia o carne de animales matados con anestesia, al menos si quisieran continuar con su comercio de venta y no renunciar a crearse un nuevo fundamento de vida. $Y$ cualquiera de estas decisiones tendría importantes consecuencias para los afectados. La decisión de limitarse a comercializar la carne de animales sacrificados sin anestesia no sólo conllevaría una renuncia a la actividad como matador, sino también la incerteza de si la carne ofrecida a la venta procedía realmente de animales sacrificados sin anestesia y si, por tanto, posibilitaba un consumo de acuerdo con las reglas de la propia fe y la fe de los clientes. La decisión de cambiar el negocio a venta de carne de animales no sacrificados tendría como consecuencia que el titular del negocio debería buscarse nuevos clientes, lo que implicaría, a la postre, un giro completo en la actividad profesional, y ello en la hipótesis de ser incluso posible en el caso concreto del afectado, y en definitiva, el afectado debería construirse otro fundamento para su existencia vital, afectando así a su libertad de profesión.

Además, en segundo lugar, pondera el TCFA que la prohibición no afecta sólo al carnicero musulmán solicitante de amparo, sino que se produce también una afectación de derechos fundamentales de terceros, en concreto, de los clientes de dicho carnicero, quienes, al demandar carne de animales sacrificados sin anestesia, es de suponer que lo hacen en la convicción de la fuerza vinculante de su fe en cuanto a no poder comer otra carne. Y dice el TCFA que no se tendrían suficientemente en cuenta las costumbres gastronómicas de la sociedad en la RFA si se exigiera de aquéllos básicamente la 
renuncia al consumo de carne, pues ésta es un alimento muy extendido y la renuncia involuntaria al mismo difícilmente puede considerarse razonable. El eventual consumo de carne importada hace superflua tal renuncia, pero conlleva, ante la falta de contacto personal con el matador y la ausencia de la base de confianza así creada, la incerteza de si la carne consumida es realmente conforme a los mandatos del Islam.

En el otro lado de la balanza, sopesa el TCFA que la protección de los animales es una exigencia del bien común al que la población concede un gran valor y ello lo tiene en cuenta el legislador cuando tutela a los animales, sobre todo por medio de la Ley de Protección de Animales, y concibe a éstos no como cosas, sino como otras criaturas, susceptibles de dolor. Pero tal protección no es absoluta en el sentido de que evite a los animales toda afectación en su bienestar, sino que simplemente parte de la directriz de que no se puede causar a los animales "dolores, sufrimientos o daños sin razones razonables" (artículo 1 de la Ley y BVerfGE 36, 47, 57; 48, 376, 389), y en consecuencia prevé excepciones al mandato general de matar a los animales con anestesia no sólo en casos como el que se estudia, sino también para las matanzas en situaciones de necesidad en que no pueda anestesiarse a los animales (artículo 4a, apartado 2, número 1 de la Ley) o respecto de los casos en que lo acuerde un reglamento para las aves (artículo 4a, apartado 2, número 3) y también respecto de vertebrados cuando aparezca como razonable en las concretas circunstancias y puedan evitarse dolores al animal (piénsese en el ejercicio lícito de la caza o en la aplicación de medidas paliativas del dolor cuando sólo se producen dolores inevitables), lo que muestra que el legislador ha considerado compatible la protección de animales con excepciones al mandato de anestesia cuando lo sugerían consideraciones objetivas o también la tradición y la aceptación social.

$\mathrm{Y}$ en tercer lugar, en una valoración conjunta, sostiene el Tribunal que también debe haber una excepción al mandato de anestesia cuando se trata de ejercer una profesión con incidencia religiosa, por un lado, y de posibilitar la observancia de preceptos gastronómicos religiosamente motivados por parte de los clientes de quien ejerce aquella profesión, por otro lado. Sin una excepción de este tipo, se restringirían irrazonablemente los derechos fundamentales de aquellos que quieren ejecutar profesionalmente sacrificios de animales sin anestesia y se daría la primacía a la exigencia de protección de los animales de una forma unilateral y sin suficiente justificación constitucional. En lugar de ello, se necesita una regulación que, de modo equilibrado, tenga presente tanto los derechos fundamentales afectados como el objetivo de la protección ética de los animales ${ }^{15}$.

15. Ello responde al principio de concordancia práctica. El concepto de "concordancia práctica" se debe a Hesse, quien considera la cuestión de los límites a los derechos fundamentales como una cuestión de fijar una "concordancia práctica" entre "las relaciones vitales protegidas por los derechos fundamentales" $\mathrm{y}$ "otras relaciones vitales que son, igual que aquellas, esenciales para 
Pues bien, a partir de estas ponderaciones explícitas, el TCFA pasa a analizar la compatibilidad con los derechos fundamentales del artículo $4 a$ de la Ley de Protección de Animales. Y sostiene, a ese respecto, el Alto Tribunal que el precepto es, en principio, y considerado en sí mismo, adecuado a estas exigencias, ya que lo que pretende es posibilitar el sacrificio sin anestesia de animales por razones religiosas (a musulmanes y judíos, sobre todo) por medio de las autorizaciones excepcionales. A través de la autorización excepcional debe, además, abrirse una vía para el control público de los sacrificios sin anestesia religiosamente motivados, en especial en la forma de los llamados sacrificios caseros y privados, lo que puede ocurrir, entre otras posibilidades, por medio de disposiciones anexas para que se ahorren al animal que haya de ser sacrificado todos los daños y sufrimientos evitables. Conforme a ello, el objetivo de la regulación es proteger los derechos fundamentales de musulmanes y judíos creyentes sin por ello renunciar al mismo tiempo a los principios y obligaciones de una protección éticamente fundada de los animales. Ello toma también debidamente en cuenta, concluye el TCFA, los derechos fundamentales del solicitante en amparo.

Sin embargo, dice el Tribunal Constitucional, ello no sería así si el citado precepto se interpreta como lo había hecho en este caso el TFA, esto es, en el sentido de que para que proceda la autorización excepcional prevista es preciso que se determine objetivamente que la Comunidad religiosa a la que pertenezca el solicitante de amparo prohíbe imperativamente el consumo de carne de animales no sacrificados sin anestesia, sin que para ello pueda ni deba atenderse a la consideración individual subjetiva de algunos de sus miembros. Tal interpretación, dice el TCFA, no toma en cuenta la significación y radio de acción del derecho fundamental a la libertad de acción (con relación a la libertad de profesión) y de religión, por cuanto que con ello se impide la actividad profesional de un carnicero que quiere sacrificar animales sin anestesia en atención a los preceptos gastronómicos de su credo y del credo de sus clientes para así asegurarse un sustento; se grava a los afectados de un

la vida de la Comunidad y por ello están, o deben estar, jurídicamente protegidas". Se trata de lograr, dice Hesse, "la coordinación "proporcional" de derechos fundamentales y bienes jurídicos limitadores de los derechos fundamentales", llevando a unos y a otros a una "vigencia óptima" y ello a partir de la consideración de las prescripciones en conflicto desde una perspectiva conjunta informada por el principio de unidad de la Constitución. Y puesto que los derechos fundamentales, incluso aunque estén sometidos a una reserva de ley, pertenecen a los componentes esenciales del orden constitucional, la fijación de esa "coordinación proporcional" no puede llevar a que se prive al derecho fundamental más de lo necesario, o incluso en su integridad, de su vigencia en la vida de la comunidad. Por ello, la limitación de un derecho fundamental ha de ser adecuada, necesaria y proporcional. En ciertos casos excepcionales, como por ejemplo una colisión de diferentes posiciones de derechos fundamentales, puede resultar inevitable al final hacer ceder a un derecho fundamental en su integridad (por ejemplo, la libertad artística frente a la libertad religiosa), lo cual "necesita, sin embargo, de una mayor fundamentación jurídica, que no se puede realizar por medio de una mera 'ponderación de bienes' insustantivada". Konrad Hesse, Grundzüge des Verfassungsrechts der Bundesrepublik Deutschland, C. F. Müller, Heidelberg-Karlsruhe, 1995, pp. 142-143. 
modo desproporcionado y sólo toma en cuenta, en realidad, de forma unilateral, las exigencias de la protección de animales. Por ello, esta interpretación del artículo 4 a de la Ley sería, a juicio del TCFA, inconstitucional.

Ello, sin embargo, no ha de llevar a la declaración de inconstitucionalidad del precepto en cuestión, pues lo único que resulta inconstitucional es la interpretación que del mismo se había hecho por el TFA en la sentencia sujeta a control, interpretación que, por lo demás, el propio TFA ya había rectificado en el momento de dictar el TCFA su sentencia. Y aquí el TCFA se refiere, en particular, a dos elementos del precepto que han de interpretarse de manera conforme a la Constitución a fin de salvar la constitucionalidad de aquél:

En primer lugar, la referencia a las "comunidades religiosas" no puede entenderse en el sentido en que se emplea ese término en el artículo 137.5 de la Constitución de Weimar, de manera que los grupos en cuestión deban cumplir los requisitos para el reconocimiento de su carácter de corporaciones de Derecho público; ni tampoco en el sentido de que hayan de estar legitimados para dar clases de religión conforme al artículo $7.3 \mathrm{LF}$, sino que, más bien, basta con que el afectado pertenezca a un grupo de personas unido por una convicción de creencias común, tal y como ha sostenido el propio TFÁ en su ulterior Sentencia de 23 de noviembre de 2000, que el TCFA cita expresamente en su Sentencia y que revisó la interpretación sustentada en la Sentencia sujeta ahora a examen del TCFA. Y son, así, comunidades religiosas a los efectos del artículo 4a de la Ley también los grupos dentro del Islam cuya orientación se diferencie del de cualesquiera otras comunidades islámicas. Esta interpretación, dice el TCFA, está en armonía con la LF y especialmente toma en cuenta la libertad religiosa; es compatible también con la literalidad del precepto y corresponde, además, a la voluntad del legislador de abrir el ámbito aplicativo del precepto no sólo a los judíos, sino también a los miembros del Islam y sus diferentes orientaciones religiosas.

En segundo lugar, y como consecuencia indirecta de lo anterior, el concepto de preceptos imperativos de la comunidad religiosa que prohíban el consumo de animales sacrificados sin anestesia no puede venir necesariamente referido, en el caso de una religión que, como el Islam, defiende diversas interpretaciones del mandato de sacrificio sin anestesia, a la religión (el Islam) en su conjunto o a las orientaciones sunitas o chítas de esta religión, sino que ba de referirse a la concreta comunidad religiosa que pueda existir en su caso dentro de una de tales orientaciones, bastando con que aquellos que solicitan la autorización excepcional a fin de proveer de carne a los miembros de una comunidad religiosa expliquen, de manera sustanciosa y comprensible, que el consumo de animales requiere de forma imperativa que se mate a los mismos sin anestesia (véase BVerwGE 94, 8287 ss.), pues si así se manifiesta, el Estado, que no puede dejar de atender a tal autoconcepción de la propia comunidad religiosa (BVerfGE 24, 236247 ss.), tiene que abstenerse de una valoración de esta concepción de la propia fe (BverfGE 33, 23, 30). 
No puede tampoco, desde luego, a juicio del TCFA, negarse carácter imperativo a una norma religiosa a la luz de la libertad religiosa por el hecho de que la religión en cuestión conozca reglas que tomen en cuenta las necesidades de conciencia de los creyentes y admitan, por ejemplo, excepciones en atención al lugar de estancia y los usos gastronómicos allí dominantes. Y ello sin perjuicio de que haya asimismo que asegurar con disposiciones normativas complementarias, y la oportuna supervisión de su observancia, que resulte garantizada en la mayor medida posible la exigencia de protección de los animales también respecto de las especiales técnicas de matanza de animales sin anestesia, al igual que ocurría con el examen de las circunstancias objetivas y la adecuación personal del solicitante.

La conclusión es, así, clara para el TCFA: las autoridades administrativas y los tribunales de lo contencioso-administrativo lesionaron el derecho fundamental a la libertad de acción (profesión) en relación a la libertad religiosa, pues han desconocido la posibilidad y la necesidad de una interpretación conforme a la Constitución de las disposiciones legales relativas a la autorización excepcional a la matanza de animales sin anestesia y han procedido a restringir de forma desproporcionada el derecho fundamental del solicitante de amparo al denegarle, primero, la autorización y confirmar luego esa decisión. Por el contrario, la autorización debió habérsele concedido al no poder excluirse que sus clientes y él mismo pertenecieran a una comunidad religiosa (en el sentido antes indicado) que les exigiera imperativamente el consumo de animales sacrificados sin anestesia; y el TCFA, en consecuencia, anula las decisiones jurisdiccionales y remite la causa al Tribunal administrativo, que deberá admitir la apelación.

\section{CONSIDERACIONES FINALES}

De una comparación de los dos casos estudiados resulta lo siguiente: a) el TEDH considera que la denegación de autorización a la asociación judía ultraortodoxa minoritaria en cuestión para sacrificar animales como les exigen a sus miembros sus creencias religiosas no es una intervención en la libertad religiosa, y con ello ya no es preciso analizar si tal intervención está justificada de conformidad con el CEDH y no se entra, pues, a controlar ya por el TEDH la observancia de las garantías propias del Estado de Derecho para la adopción de tal medida, sino que simplemente se concluye que la libertad religiosa no ha sido afectada, conclusión, por lo demás, poco convincente a la vista de la realidad de que a los ciudadanos afectados no se les permitirá ejecutar animales sin anestesia con el control exbaustivo que les exigen sus creencias religiosas, mientras que a los ciudadanos de la misma religión pero pertenecientes a la comunidad mayoritaria se les ha autorizado el sacrificio de animales sin anestesia, que realizan, sin embargo, sin el control más exhaustivo de la sangre existente en los pulmones del animal sacrificado que a los 
feligreses más ortodoxos de la asociación minoritaria exige su creencia religiosa; b) en cambio, en el caso alemán, se considera que la denegación a un carnicero extranjero musulmán de una autorización excepcional para proceder al sacrificio de animales sin anestesia que le exige su propio credo y el de sus clientes conlleva, aún tratándose de un extranjero, una intervención en la libertad de profesión (protegida por la libertad general de acción) así como en la propia libertad religiosa.

El análisis de las dos sentencias del TEDH y el TCFA pone, así, de relieve no sólo una discrepancia en el concreto alcance que uno y otro tribunal dan a la libertad religiosa con relación al sacrificio ritual de animales, con el resultado de un estándar nacional de protección más alto que el europeo, sino también, desde un punto de vista dogmático más general, la distinta amplitud que dan uno y otro tribunal al concepto de intervención o injerencia en los derechos fundamentales y también, en el fondo, la distinta concepción que tienen ambos tribunales respecto del ámbito normativo o "tipo iusfundamental" de la libertad religiosa en este campo de los sacrificios rituales por motivos religiosos de animales ${ }^{16}$, pues mientras el TCFA sigue una concepción más amplia del ámbito normativo del derecho fundamental y entiende que la libertad religiosa, precisamente, impide al Estado entrar a valorar las creencias religiosas de los ciudadanos y le exige atender a su propia (auto)concepción de la religión, en el caso del TEDH, en cambio, no sólo se lleva a cabo, en el fondo, esa valoración respecto de las creencias profesadas por los miembros de la asociación que impetra su amparo, sino que tal valoración lleva al Tribunal a negar, ya de entrada, la existencia de una interferencia en la libertad religiosa de la asociación demandante por denegársele por las autoridades administrativas del Estado una autorización para practicar el sacrificio de animales en la forma exigida por sus creencias, con lo cual deviene innecesario analizar ya la justificación conforme al CEDH de la medida en cuestión (en concreto, el respeto a la reserva de legalidad y al principio de proporcionalidad por parte de las autoridades francesas).

Así, se pone de relieve la importancia de que se siga (o no) un concepto amplio tanto del ámbito normativo de un derecho fundamental, como también de la intervención o injerencia en el mismo, pues quien tiende a seguir una concepción estrecha del ámbito normativo o de la injerencia ${ }^{17}$ también tende-

16. Dice, así, con razón, Christine Langenfeld ("Germany", cit., p. 145): “A la vista del razonamiento bien diverso del Tribunal Constitucional alemán [respecto al del TEDH], resulta dudoso si habría adoptado [éste] el mismo enfoque restrictivon.

17. En realidad, puede decirse que la concepción estrecha de la injerencia o intervención en los derechos fundamentales se corresponde con la concepción estrecha también del ámbito normativo o "tipo" de los derechos fundamentales, pues quien defiende una concepción estrecha del tipo iusfundamental excluye ya de entrada con esa delimitación tan estricta del "tipo" muchos supuestos de hecho de la aplicación del derecho fundamental, por lo que podrá defender un concepto estrecho de intervención, pero también puede ocurrir que alguien defienda una concepción amplia del tipo iusfundamental, pero luego siga una concepción estrecha de la intervención, con lo cual también excluirá el examen sustantivo de fondo de la justificación material de la medi- 
rá a resolver en la fase del ámbito normativo o la injerencia, casi sin argumentación, cuestiones que quienes tienden a una concepción amplia del ámbito normativo o de la injerencia, por el contrario, tenderán a resolver en una fase ulterior, la de justificación de la medida, que requerirá un control riguroso y a fondo del respeto de unos exigentes requisitos, en especial, la reserva de ley y el principio de proporcionalidad.

Cuando ello se refiere a cuestiones que no sean polémicas o que no lo sean más que en escasa medida (en el seno del propio Tribunal, de la sociedad o de la comunidad científica), no habrá acaso gran diferencia entre seguir una u otra concepción, pero cuando, por el contrario, como en el caso resuelto por el TEDH, la cuestión a resolver se refiera a asuntos polémicos en el seno del propio Tribunal (y así lo revela objetivamente el voto particular de siete magistrados), de la sociedad y de la propia comunidad científica, la solución ofrecida por los seguidores de una concepción estrecha del ámbito normativo o del concepto de injerencia en el mismo resultará insatisfactoria, al menos formalmente, pues excluirá la ponderación de las razones a favor y en contra de la medida y el control de la observancia de la reserva de ley en un asunto en que tal argumentación debería haber entrado en juego.

Se pasa, así, por alto que lo decisivo es la afectación con incidencia restrictiva del ámbito "prima facie" protegido por el derecho fundamental, que debería requerir una justificación y un control lo más riguroso posible, tanto más cuando no exista al respecto un consenso básico, pues sólo el razonamiento exhaustivo puede contribuir a legitimar las decisiones jurisdiccionales en este campo y a convencer a todos de la justicia y corrección de la solución propuesta, además de que sólo cuando tal medida está suficientemente amparada por una ley parlamentaria se respetará el principio democrático de que sean los propios ciudadanos los únicos que, por medio de sus legítimos representantes, se (auto)impongan restricciones a sus libertades fundamentales.

Es claro, pues, que la sentencia del TCFA y la del TEDH, aun resolviendo casos diversos, no sólo llegan a soluciones difícilmente compatibles por los argumentos en que se basan, sino que puede sostenerse, con un alcance dogmático más general, que el TEDH sigue, al menos en este concreto campo de los sacrificios sin anestesia de animales de consumo humano, una concepción más estrecha del ámbito normativo o "tipo" de la libertad religiosa y también un concepto bastante estrecho de intervención en los derechos fundamentales, con la consecuencia de que resuelve con un déficit de fundamentación jurídica una cuestión altamente problemática no sólo para las partes en el proceso, sino también para los propios magistrados integrantes del TEDH y para la opinión pública.

da y el control de la observancia de la reserva de ley en muchos supuestos de hecho, con lo cual seguirá una concepción estrecha del ámbito normativo o tipo iusfundamental, entendido éste en un sentido amplio, comprensivo también de la intervención. 
Es sólo un ejemplo de las consecuencias que, en los casos particulares, puede tener el seguir una concepción estrecha del ámbito normativo o "tipo" de los derechos fundamentales o de la intervención en los mismos y ello incluso en el supuesto de que la solución material de fondo a que se llegue por esta vía sea la más acertada (lo que es, por lo menos, muy cuestionable en este caso), pues, incluso en la mejor de las hipótesis, se sustraerá en buena medida del debate racional una cuestión compleja, problemática y discutida; se eludirá, además, una vía para lograr un mayor consenso racional en el seno del Tribunal; se dificultará, así, también lograr el consenso y aceptación sociales de que están necesitadas las resoluciones judiciales; y, por último, se hará más difícil llegar a una solución material lo más racional y satisfactoria posible.

Todo ello habla, junto a otras razones, en favor de seguir una concepción amplia tanto del ámbito normativo o "tipo" de los derechos fundamentales como de la intervención en los mismos, como lo sería la defendida por el TCFA en la sentencia comentada. En una comparación de esta última con la sentencia dictada por el TEDH para un supuesto parecido se ponen de relieve las consecuencias de todo orden que pueden derivarse de seguir una concepción estrecha del ámbito normativo o "tipo" de los derechos fundamentales o del concepto de intervención o injerencia en los mismos por contraste con lo que ocurre cuando se sigue una concepción amplia de aquéllos: control menos riguroso y exhaustivo, menor posibilidad de acuerdo en el seno del Tribunal, solución de fondo menos fundamentada y menos convincente racionalmente, aparte ya de la disminución de las posibilidades de alcanzar una solución materialmente satisfactoria y las posibilidades crecientes de discrepancia en el seno del propio Tribunal (véase, a este respecto, el voto particular de los siete magistrados a la STEDH comentada), al excluirse, en realidad, por la mayoría el debate de prácticamente toda cuestión relativa a los derechos fundamentales. 